\title{
Assessment of children's exposure to currently used pesticides in wallonia, Belgium
}

\author{
Catherine Pirard ${ }^{\mathrm{a}, *}$, Suzanne Remy ${ }^{\mathrm{b}}$, Arnaud Giusti ${ }^{\mathrm{b}}$, Léa Champon ${ }^{\mathrm{b}}$, Corinne Charlier ${ }^{\mathrm{a}}$ \\ ${ }^{a}$ Laboratory of Clinical, Forensic and Environmental Toxicology, CHU of Liege, B35, 4000 Liege, Belgium \\ ${ }^{\mathrm{b}}$ Direction of Chronic Risks, Environment and Health Team, Scientific Institute of Public Service (ISSeP), Rue du Chera 200, 4000 Liege, Belgium
}

\section{A R T I C L E I N F O}

\section{Keywords:}

Biomonitoring

Children

Currently used pesticides

Ambient air

Belgium

\begin{abstract}
A B S T R A C T
In spring 2016, a study was carried out to characterize currently used pesticide (CUP) exposure among children living in Wallonia (Belgium). Pesticides were measured in both first morning urine voids of 258 children aged from 9 to 12 years and in ambient air collected close to the children's schools. Out of the 46 pesticides measured in the air, 19 were detected with frequencies varying between $11 \%$ and $100 \%$, and mean levels ranging from $<0.04$ to $2.37 \mathrm{ng} / \mathrm{m}^{3}$. Only 3 parent pesticides were found in $1-10 \%$ of the urine samples, while all the metabolites analyzed were positively detected at least once. The captan metabolite (THPI) was quantified in 23.5 $\%$ of the samples, while 3,5,6-trichloro-2-pyridinol (chlopryrifos metabolite) was detected in all urines with levels ranging from 0.36-38.96 $\mu \mathrm{g} / \mathrm{l}$. 3-phenoxybenzoic acid (3-PBA), trans-3-(2,2-dichlorovinyl)-2,2-dimethylcyclopropane carboxylic acid (t-DCCA) and diethylphosphate were the most abundant pyrethroid metabolites and dialkylphosphate measured. The air inhalation was demonstrated to be a minor route of exposure for the selected CUPs. Statistical regressions highlighted predictors of exposure for some pesticides such like consumption of grey bread, presence of carpets at home or indoor use of pesticides, although no clear source was identified for most of them.
\end{abstract}

\section{Introduction}

Beside China, South and Central America, Europe ranked this past decade as the third area in the world where the use of pesticides per area of cropland is the highest, and despite the different regulations and directives implemented to reduce pesticide adverse effects on human health and environment, the average use per area continued to increase between 2010 and 2016 (FAOSTAT, 2019). Within Europe, Belgium was the second pesticide user per area of cropland just behind the Netherlands with $6.89 \mathrm{~kg}$ of pesticides used per ha in 2016 while the European average was evaluated at $1.67 \mathrm{~kg} / \mathrm{ha}$, demonstrating an intensive use of such potentially harmful substances in Belgium.

The assessment of the human exposure to currently used pesticides (CUPs) used to be challenging. Different measurement strategies can be used for the exposure characterization. The mains used to include questionnaires, environmental monitoring, or biomonitoring. Briefly, the questionnaires try to collect information affecting the individual exposure such like demographic characteristics, lifestyle activities, diet habits or recent food consumption; the environmental monitoring involves the measurement of multiple environmental media for instance food, drinking water, air, soil, or dust; and the human biomonitoring (HBM) consists in the determination of the chemical's human body burden through the analysis of biomarkers in human fluids or tissues (Bradman and Whyatt, 2005; Needham et al., 2005). If all these strategies have their own advantages and disadvantages as reviewed by Needham et al. (2005), and are often complementary, HBM has been nowadays commonly considered as the major tool to efficiently and cost effectively assess the human exposure to environmental pollutants including pesticides, mainly because integrating all routes of exposure, taking into account inter-individual variations, providing information

\footnotetext{
Abbreviations: CUP, currently used pesticide; HBM, human biomonitoring; OP, organophosphorous; LC, Liquid Chromatography; GC, Gas Chromatography; MS,

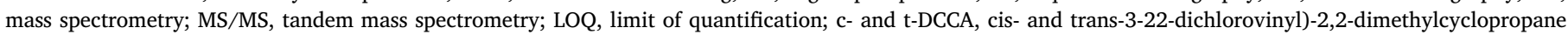

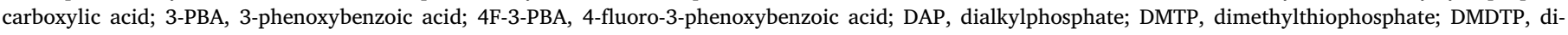

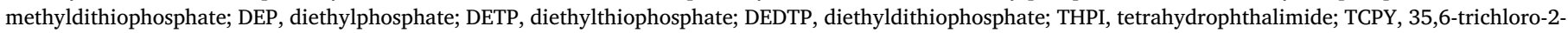

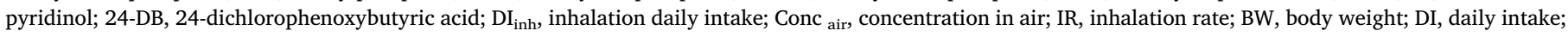
ADI, acceptable daily intake

* Corresponding author at: Laboratory of Clinical, Forensic and Environmental Toxicology, BC + 3, Porte 166, CHU (B35), 4000 Liege, Belgium.

E-mail address: c.pirard@chuliege.be (C. Pirard).
} 


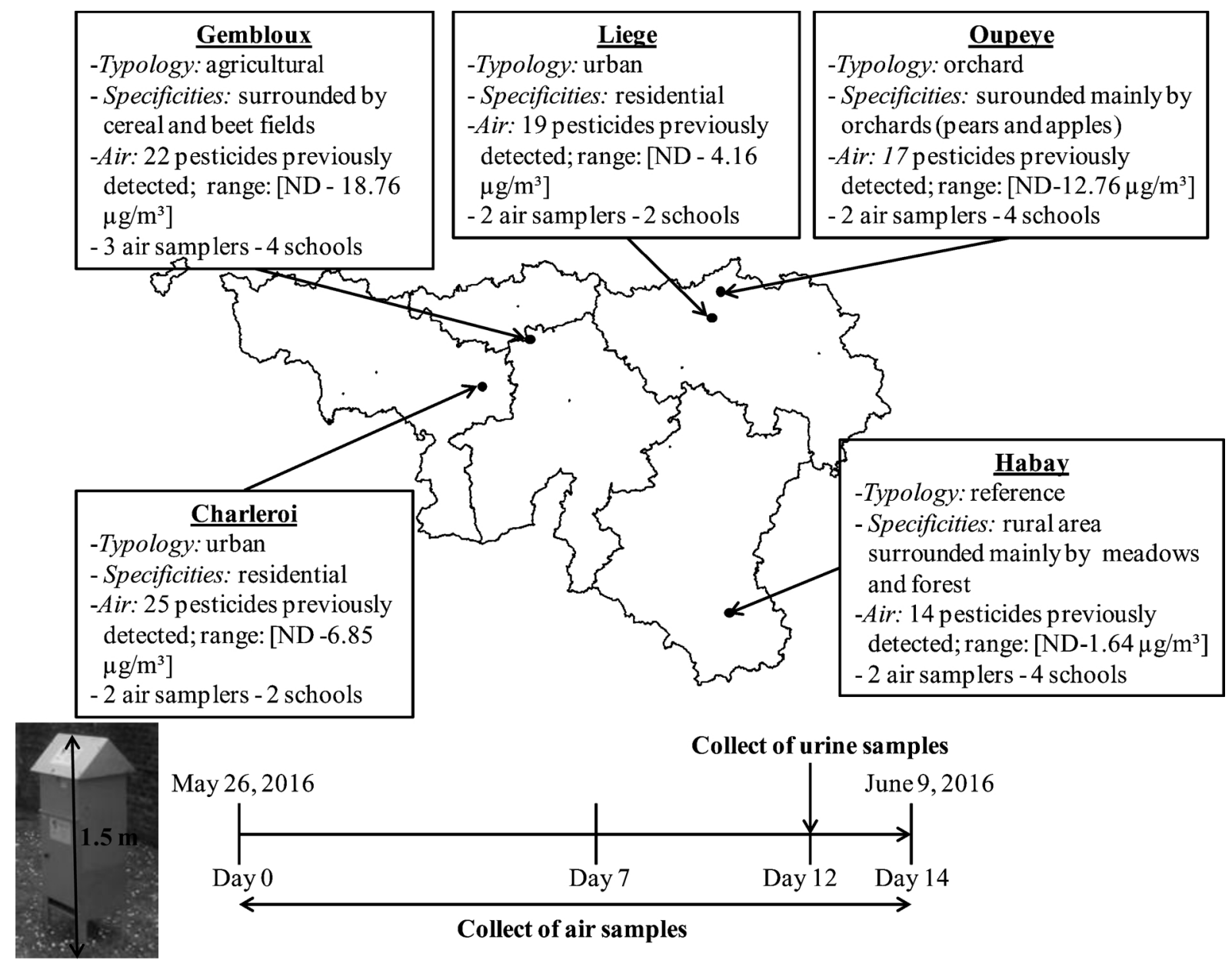

Fig. 1. Characteristics of the selected sites and timing of the sampling.

on spatial and temporal trends, reporting levels more directly related to potential adverse health outcomes, etc (Angerer et al., 2007; Egeghy et al., 2011; World Health Organization (WHO), 2019). However, a thorough knowledge of the human pharmacokinetic of the target chemicals is required to monitor in the appropriate media the relevant biomarkers reflecting the exposure (Barr, 2008).

Although the exposure to some pesticides such like pyrethroids or organophosphorous (OP) has already been studied worldwide through HBM studies, either in the general or in highly exposed populations including children (Kavvalakis and Tsatsakis, 2012; Morgan, 2012; Saillenfait et al., 2015; Yusa et al., 2015), only few recent results have been reported from children living in Western Europe. More specifically in Belgium, to our knowledge, the only available data were produced several years ago, focused on some OP metabolites and concerned Flemish children (Schoeters et al., 2011) whereas in Wallonia, HBM surveys are only under development and up to now have been not focused on CUPs.

On the other hand, if one of its strengths is to integrate all routes of exposure, HBM does not provide direct information about the identification of sources. For pesticides, even if the human exposure for the general population is thought to mainly occur through food ingestion (Sheldon, 2006), the importance of the diet contribution in the overall exposure could vary according to the extent of other sources such like the vicinity of agricultural fields, the occupational status of the family members, the domestic use of pesticides, etc (Curl et al., 2002; Holme et al., 2016; Trunnelle et al., 2014). Moreover, if some intervention studies substituting conventional to organic diet highlighted a drastic decrease of the levels of pesticide biomarkers in the urine of participants, a residual contamination was observed (Bradman et al., 2015;
Göen et al., 2017; Lu et al., 2006a), suggesting other minor but non negligible routes of exposure. Because pesticides have been detected in ambient air either from rural, urban, or remote areas (Coscollà et al., 2010; Kurt-Karakus et al., 2011; LeNoir et al., 1999; Mai et al., 2013), the question about the importance of the inhalation contribution to the overall non occupational exposure should be raised. Few works tried to link the outdoor contamination and body burden levels of residents (Galea et al., 2015; Koch et al., 2002; Phung et al., 2012) but none of them perform ambient air measures to quantify the levels of this exposure pathway.

Therefore in order to fill the gap of HBM data focused on pesticides in Belgium and more specifically in Wallonia, and to assess the contribution of inhalation at environmental levels as exposure pathway, a study combining the measures of ambient air and urinary levels of CUPs was carried out in Wallonia. Children were selected as subpopulation because their exposure is of particular concern, experiencing higher exposure due to their specific diet, behaviors and activities, or their higher dose to weight ratio (Weiss et al., 2004). Preliminarily to the present study, a one-year measurement campaign (from 2015 to 2016) of CUPs in ambient air was carried out in 12 different locations spread over Wallonia, and characterized by different agricultural practices and pesticide uses (remote areas with no use of pesticides, urban sites, agricultural sites, livestock areas, sites surrounded by parks, gardens or railways where pesticide uses were suspected, etc). The 46 pesticides analyzed in air were selected according to the ranking method described earlier (Giusti et al., 2018) mainly based on toxicology endpoints, sales and uses at the national and regional levels, and their significant probability to be detected in air. The results of this previous study allowed to select the timing and the locations where air and urine 
samples will be collected.

\section{Materials and methods}

\subsection{Sample collection}

Five sites were selected because showing contrasted pesticide profiles and concentrations in ambient air during the previous one-year measurement campaign, and the time of the sampling (May - June) corresponded to the period where the highest levels were measured in all sites. The location and characteristics of the sites are described in Fig. 1. For each site, between 2 and 3 air samplers placed in the close vicinity of the participating schools (between 2 and 4 schools per locality were involved in this study) collected samples during 14 days, from May 26th to June 7th 2016, at a $4 \mathrm{~m}^{3} / \mathrm{h}$ flow (meaning a total volume of $1344 \mathrm{~m}^{3}$ collected by sampler) using Total Suspended Particulate High Volume Samplers (ThermoFisher scientific, Breda, The Netherlands). These 11 samplers were $1.5 \mathrm{~m}$ high (see picture on Fig. 1) and laid on the ground except one in Oupeye placed on the roof of the school. They were equipped with a quartz filter (Pallflex, PallLife Science, Hoegaarden, Belgium) and a cartridge filled with ORBO 2500 precleaned large PUF/Amberlite ${ }^{\circledR} \mathrm{XAD}^{\circledR}$-2/PUF from Supelco (Bellefonte, PA, USA). Additionally, some Quality Controls and field blanks consisting in virgin cartridge (filled with PUF/XAD/PUF resin) respectively spiked and non-spiked with standard solution containing all analytes were run to ensure the reliability of the analysis and the absence of external contamination. All cartridges and filters were stored in the dark at $4{ }^{\circ} \mathrm{C}$ until extracted.

Children living in the selected localities and aged from 9 to 12 years old were invited to participate via their school on voluntary basis. The only inclusion criteria were to attend schools participating to the study (and thus located near an air sampler) and to be aged between 9 and 12 years old. Once the participation accepted, the parents signed the informed consent, and answered to a questionnaire about their home environment, family socioeconomic status, child outside activities, diet habits, domestic uses of pesticide, and to a diet questionnaire $(48 \mathrm{~h}$ recall). They were asked to collect the first morning urine void of their children on June 7th 2016 in a $250 \mathrm{ml}$ polypropylene vessel previously distributed (all urine samples were collected the same day, except in Oupeye where the collect was performed on June 14th due to some administrative delays, thus air samples were collected from June 2nd to 16th). However in each site, the air samples were collected from 12 days before to 2 days after the urine collection (Fig. 1). The urine samples were transferred to the laboratory at refrigerated temperature $\left(4-6{ }^{\circ} \mathrm{C}\right.$ ), and were stored at $-20^{\circ} \mathrm{C}$ before analysis. All communication documents were derived from those used during the COPHES/ DEMOCOPHES study (Joas et al., 2012).

\subsection{Analytical procedure}

The air analyses were carried out by the Scientific Institute of Public Service (ISSeP) and the Walloon Center of Agronomical Research (CRAW), while urine samples were analyzed by the Laboratory of Toxicology (CHU Liege).

\subsubsection{Air samples}

The 46 pesticides previously selected (Giusti et al., 2018) are gathered in Table 1 . The extraction of pesticides from filters and cartridges was carried out for $4 \mathrm{~h}$ using an hexane:acetone:methanol mixture (50:40:10 v:v:v) in a Soxhlet apparatus. Solvent volume was then reduced to $10 \mathrm{ml}$ using rotary evaporator, and split into 2 fractions of $5 \mathrm{ml}$ dedicated to respectively Liquid Chromatography (LC) and Gas Chromatography (GC) coupled to mass spectrometry (MS) analyses. Further concentration and reconstitution of both extracts are detailed in Supplementary material as well as all LC-tandem mass spectrometry (MS/MS) and GC-MS/MS gradients and parameters. The quantification
Table 1

Mean recoveries obtained during the validation, and limits of quantification (LOQs) for each of the 46 pesticides measured in air.

\begin{tabular}{llllll}
\hline Analyte & $\begin{array}{l}\text { Mean } \\
\text { recovery } \\
(\%)\end{array}$ & $\begin{array}{l}\text { LOQ } \\
(\mathrm{ng} / \\
\left.\mathrm{m}^{3}\right)\end{array}$ & Analyte & $\begin{array}{l}\text { Mean } \\
\text { recovery } \\
(\%)\end{array}$ & $\begin{array}{l}\text { LOQ } \\
(\mathrm{ng} / \\
\left.\mathrm{m}^{3}\right)\end{array}$ \\
\hline 2,4 D & 85 & 0.04 & Fenpropidin & 82 & 0.04 \\
2,4 DB & 109 & 0.10 & Fenpropimorph & 72 & 0.04 \\
Aclonifen & 67 & 0.10 & Iprodione & 71 & 0.04 \\
Benfluralin & 76 & 0.04 & Kresoxim-methyl & 78 & 0.04 \\
Boscalid & 128 & 0.04 & Linuron & 126 & 0.04 \\
Captan & 72 & 0.04 & MCPA & 98 & 0.04 \\
Chlorothalonil & 88 & 0.10 & Metazachlor & 83 & 0.04 \\
Chlorpyrifos-ethyl & 79 & 0.04 & S-Metolachlor & 113 & 0.04 \\
Clopyralid & 67 & 0.10 & Metribuzin & 91 & 0.04 \\
Cyhalothrin & 87 & 0.04 & Myclobutanil & 74 & 0.04 \\
Cymoxanil & 92 & 0.04 & Oxadiazon & 90 & 0.04 \\
Cypermethrin & 80 & 0.04 & Penconazole & 81 & 0.04 \\
Cyproconazole & 102 & 0.04 & Pendimethalin & 98 & 0.10 \\
Cyprodinil & 86 & 0.04 & Pirimicarb & 87 & 0.10 \\
Deltamethrin & 70 & 0.04 & Propiconazole & 92 & 0.10 \\
Difenoconazole & 78 & 0.04 & Propyzamide & 73 & 0.10 \\
Diflufenican & 66 & 0.04 & Prosulfocarb & 77 & 0.10 \\
Dimethenamid-P & 87 & 0.04 & Pyrimethanil & 78 & 0.04 \\
Dimethoate & 78 & 0.04 & Spiroxamine & 79 & 0.04 \\
Epoxiconazole & 94 & 0.04 & Terbuthylazine & 94 & 0.04 \\
Ethofumesate & 94 & 0.10 & Tebuconazole & 80 & 0.04 \\
Ethoprophos & 65 & 0.10 & Tetraconazole & 92 & 0.04 \\
Fenoxycarb & 80 & 0.04 & Triallate & 97 & 0.10 \\
\hline
\end{tabular}

of the analytes detected by LC/MS was performed using isotope dilution (internal standards are reported in Table S1) with spiked calibration curves ranging from $0.5-40 \mathrm{pg} / \mu \mathrm{l}$, while those determined by GC were quantified using the method of external standard addition (sample unspiked and spiked at 5 increasing levels from 5 to $100 \mathrm{ng} / \mathrm{ml}$ ). The recoveries were determined on cartridges spiked at 3 levels each in duplicate (50, 500 and $1000 \mathrm{ng}$ ), and the means ranged between 72 and $128 \%$ in the dosing range, except for aclonifen, clorpyralid, diflufenican, and ethoprofos for which recoveries were slightly lower (Table 1). The limits of quantification (LOQs) were determined based on the recovery rates and the signal to noise ratio $(S / N>10)$. LOQs for both LC and GC methods were 0.04 or $0.1 \mathrm{ng} / \mathrm{m}^{3}$ depending on the pesticide (Table 1).

\subsubsection{Urinary analyses}

The 43 pesticides or metabolites prioritized for the biomonitoring part of the study are gathered in Table 2 . Compared to parent pesticides measured in air, chlorothalonil, cymoxanil, fenpropimorph and pyrimethanil were not included in the urinary analysis because of the non suitability of the multi-analyte method for these substances. In addition were also included 4 non specific metabolites of pyrethroid insecticides namely cis- and trans-3-(2,2-dichlorovinyl)-2,2-dimethylcyclopropane carboxylic acids (c- and t-DCCA), 3-phenoxybenzoic acid (3-PBA) and 4-fluoro-3-phenoxybenzoic acid (4F-3-PBA), and 5 dialkylphosphates (DAPs) as non specific metabolites of OP pesticides namely dimethylthiophosphate (DMTP), dimethyldithiophosphate (DMDTP), diethylphosphate (DEP), diethylthiophosphate (DETP), diethyldithiophosphate (DEDTP). The 43 biomarkers were determined using 3 different extraction procedures detailed in Supplementary material, and analyzed by LC-MS/MS, GC-MS/MS, or GC-MS/MS after a derivatization step. For all compounds, the quantification was performed using a matrix-matched calibration curve built in real urine from anonymous donors (previously checked for initial contamination) fortified at different levels, excepted for DAP and pyrethroid metabolite analyses for which synthetic urine (Ricca Chemical, Arlington, TX, USA) was used. The 3 analytical methods were validated according to the total error approach (Dubois et al., 2012; Hubert et al., 2007) using E-noval software V4.0 (Arlenda, Liege, Belgium), and based on the standard 
Table 2

Trueness and limits of quantification (LOQs) obtained during the validation for each of the 43 pesticides or metabolites measured in urine.

\begin{tabular}{|c|c|c|c|c|c|}
\hline Analyte & Trueness (\%) & LOQ $(\mu \mathrm{g} / \mathrm{l})$ & Analyte & Trueness (\%) & LOQ $(\mu \mathrm{g} / \mathrm{l})$ \\
\hline \multicolumn{6}{|l|}{ Parent pesticides } \\
\hline $2,4-\mathrm{DB}$ & 105.6 & 0.15 & Propiconazole & 104.2 & 0.14 \\
\hline Aclonifen & 114.4 & 0.18 & Propyzamide & 113.5 & 0.05 \\
\hline Benfluralin & 116.4 & 0.45 & Prosulfocarb & 106.4 & 0.14 \\
\hline Boscalid & 106.3 & 0.05 & Spiroxamine & 92.5 & 0.06 \\
\hline Captan & 107.4 & 0.50 & Tebuconazole & 103.6 & 0.05 \\
\hline Chlorpyrifos ethyl & 107.2 & 0.29 & Terbuthylazine & 101.3 & 0.05 \\
\hline Cyhalothrin & 98.4 & 0.92 & Tetraconazole & 101.0 & 0.07 \\
\hline Cyproconazole & 99.8 & 0.08 & Triallate & 103.3 & 0.24 \\
\hline Cyprodinil & 103.4 & 0.21 & Specific metabolites & & \\
\hline Difenoconazole & 104.7 & 0.17 & Desethylterbuthylazine & 105.6 & 0.05 \\
\hline Dimethenamid & 105.3 & 0.20 & TCPY & 114.2 & 0.08 \\
\hline Dimethoate & 104.4 & 0.06 & Tetrahydrophthalimide (THPI) & 85.6 & 0.20 \\
\hline Epoxiconazole & 104.4 & 0.17 & Dialkylphosphates (DAPs) & & \\
\hline Ethoprophos & 102.8 & 0.20 & Diethylphosphate & 94.2 & 0.50 \\
\hline Fenoxycarb & 99.8 & 0.18 & Diethylthiophosphate & 95.0 & 0.50 \\
\hline Fenpropidin & 107.6 & 0.05 & Diethyldithiophosphate & 98.9 & 0.50 \\
\hline Kresoxy-methyl & 101.0 & 0.72 & Dimethylthiophosphate & 88.8 & 0.50 \\
\hline Linuron & 109.4 & 0.05 & Dimethyldithiophosphate & 89.7 & 0.50 \\
\hline Metolachlor & 95.8 & 0.19 & Pyrethroid metabolites & & \\
\hline Metribuzin & 103.9 & 0.20 & c-DCCA & 105.9 & 0.50 \\
\hline Oxadiazon & 99.3 & 0.23 & $\mathrm{t}-\mathrm{DCCA}$ & 109.1 & 0.15 \\
\hline Penconazole & 94.6 & 0.40 & 4-F-3-PBA & 106.7 & 0.11 \\
\hline Pendimethalin & 100.4 & 0.12 & 3-PBA & 97.5 & 0.09 \\
\hline
\end{tabular}

addition method. The LOQs gathered in Table 2 were the smallest concentrations determined in fortified urine (or synthetic urine) samples measurable with a total error not exceeding $30 \%$. Trueness assessed on urine samples (or synthetic urine) fortified at 8 different levels, each level analyzed in triplicate, was also reported in Table 2. All analysis sequences consisted in the calibration curve, 30 unknown samples, 1 procedural blank, and 2 home-made Quality Controls (urine spiked at low and high levels). For DAP, TCPY and pyrethroid metabolite analyses, 2 additional materials from previous German External Quality Assessment Scheme (G-EQUAS) programs were added to the sequence. The complete analytical information is detailed in Supplementary material.

\subsection{Calculation of the daily intake doses through inhalation}

The inhalation daily intake doses were estimated for the pesticides detected in air in each location with the following relation:

$\mathrm{DI}_{\mathrm{inh}}(\mathrm{ng} / \mathrm{kg} / \mathrm{d})=\mathrm{Conc}_{\text {air }}\left(\mathrm{ng} / \mathrm{m}^{3}\right) \times \mathrm{IR}\left(\mathrm{m}^{3} / \mathrm{d}\right) / \mathrm{BW}(\mathrm{kg})$ where $\mathrm{DI}_{\text {inh }}$ was the inhalation daily intake, Conc air the mean concentration measured according to the location, IR the inhalation rate and BW the body weight, both set respectively at $12 \mathrm{~m}^{3} / \mathrm{d}$ and $31.8 \mathrm{~kg}$ as suggested for children aged from 6 to 11 years old (US EPA, 2015).

\subsection{Statistical analyses}

The statistical analyses were performed using SAS 9.4 for Windows (SAS Institute, Cary, NC, USA) and R 3.3.1. software (R Foundation for Statistical Computing, Vienna, Austria). All urinary biomarkers showing quantification frequency $(\mathrm{N}>$ LOQ) lower than $50 \%$ were used as dichotomized variables (detected vs non-detected) whereas they were considered as quantitative variables when their quantification frequencies were higher or equal to $50 \%$, with the measurements below the LOQ replaced by LOQ/2 (Hornung and Reed, 1990). For each urinary biomarker, the normality of the distribution was numerically evaluated by comparing medians and arithmetic means, graphically with the shape of the histogram and the Quantile Plot, and using the Shapiro-Wilk test. Due to their skewed distribution, the biomarker levels were log-transformed before being used in further statistical models to approximate a normal distribution. Univariate logistic and linear regressions were firstly carried out to compare respectively qualitative and quantitative biomarker concentrations according to the home characteristics, the socio-demographic characteristics, the children's activities and the diet characteristics, these information being collected through the questionnaire. The covariates significantly associated (statistical significance was set at $\mathrm{p}<0.05$ ) were then included in a binary logistic regression analysis or a linear multivariate model depending on the binary or the continuous character of the pesticide measure variable.

\section{Results}

Among the 258 children recruited, 29 and 12 did not answer respectively to the general and the $48 \mathrm{~h}$ recall questionnaire, while the residence area for 3 of them was not identified, and the collect of the urine of one of them was missed. Some of their characteristics are detailed in Table 3. Their mean age was $10.8+/-1.05$ years old whereas their median body mass index (BMI) was $16.7 \mathrm{~kg} / \mathrm{m}^{2}$. Most of them lived in a house (95.2\%), without carpet (93.9\%) but with at least one rug for half of them (52.4\%). A large majority of parents were originated from Belgium (88.2 \% for mothers, and $82.4 \%$ for fathers), with a fair socio-economical status (both in terms of educational levels and household income). Within the 2 days before the urine collection, 91.3 $\%$ of the children had outdoor activities, while $29.3 \%$ reported to bite their nails.

The detection rates ( $\%>$ LOQ), the mean levels (average of 2 or 3 samples depending on the site) of pesticides measured in ambient air, and the estimated inhalation daily intake doses were gathered in Table 4 according to the sampling location. All other pesticides not reported in this table were never detected. 19 pesticides out of the 46 initially measured in air were detected with rates varying between 11 and $100 \%$.

The pesticides and metabolites positively detected in the urine of children are gathered in Table 5 . While the parent pesticides and some metabolites were analyzed in all urine samples, DAP, pyrethroid metabolites, tetrahydrophthalimide (THPI) and TCPY were measured in urine with sufficient remaining volume (240 for DAP, 229 for the other metabolites). Some interferences (ion ratio between Multiple Reaction Monitoring transitions out of range) resulting in non-exploitable results were observed in 9 samples for t-DCCA and THPI, 23 and 24 samples for c-DCCA and DMTP respectively. From the 32 parent pesticides 
Table 3

Characteristics of the population of children studied.

\begin{tabular}{|c|c|c|c|}
\hline & $\begin{array}{l}\text { N children } \\
(\%)\end{array}$ & & $\mathrm{N}$ children (\%) \\
\hline Total & $258(100 \%)$ & \multicolumn{2}{|l|}{ Type of dwelling } \\
\hline Gender & & House & $218(95.2 \%)$ \\
\hline Girls & $121(48 \%)$ & Appartment & $11(4.8 \%)$ \\
\hline Boys & $131(52 \%)$ & \multicolumn{2}{|l|}{ Number of pets } \\
\hline Locations & & 0 & $106(46.3 \%)$ \\
\hline Habay (Reference) & $29(11.2 \%)$ & 1 & $57(24.9 \%)$ \\
\hline Charleroi (Urban 1) & $26(10.1 \%)$ & 2 & $27(11.8 \%)$ \\
\hline Liege (Urban 2) & $\begin{array}{l}105(40.7 \\
\%)\end{array}$ & $>2$ & $39(17.0 \%)$ \\
\hline Gembloux (Agricultural) & $54(20.9 \%)$ & \multicolumn{2}{|c|}{ Use of pet antiparasitics } \\
\hline Oupeye (Orchard) & $40(15.5 \%)$ & Yes & $75(32.8 \%)$ \\
\hline Undefined & $3(1.2 \%)$ & No & $154(67.2 \%)$ \\
\hline \multicolumn{2}{|c|}{ Educational level of the mother } & \multicolumn{2}{|c|}{$\begin{array}{l}\text { Usual proportion of organic vegetables } \\
\text { in the diet }\end{array}$} \\
\hline Primary or secondary & $56(24.5 \%)$ & $<50 \%$ & $199(86.9 \%)$ \\
\hline higher short cycle & $66(28.8 \%)$ & $>50 \%$ & $30(13.1 \%)$ \\
\hline $\begin{array}{l}\text { higher long cycle or } \\
\text { university }\end{array}$ & $\begin{array}{l}107(46.7 \\
\%)\end{array}$ & $\begin{array}{l}\text { Vegetables washed } \\
\text { consumption }\end{array}$ & dd/or peeled before \\
\hline \multicolumn{2}{|c|}{ Educational level of the father } & Never / rarely & $1(0.4 \%)$ \\
\hline Primary or secondary & $69(30.1 \%)$ & Often / always & $228(99.6 \%)$ \\
\hline higher short cycle & $45(19.7 \%)$ & \multicolumn{2}{|c|}{$\begin{array}{l}\text { Usual proportion of organic fruits in the } \\
\text { diet }\end{array}$} \\
\hline $\begin{array}{l}\text { higher long cycle or } \\
\text { university }\end{array}$ & $\begin{array}{l}115(50.2 \\
\%)\end{array}$ & $<50 \%$ & $195(85.2 \%)$ \\
\hline \multicolumn{2}{|c|}{ Net monthly income (household) } & $>50 \%$ & $34(14.8 \%)$ \\
\hline$<1999 €$ & $29(12.7 \%)$ & \multicolumn{2}{|c|}{$\begin{array}{l}\text { Fruits washed and/or peeled before } \\
\text { consumption }\end{array}$} \\
\hline $2000-3999 €$ & $97(42.5 \%)$ & Never / rarely & $21(9.2 \%)$ \\
\hline$>4000 €$ & $\begin{array}{l}102(44.7 \\
\%)\end{array}$ & Often / always & $208(90.8 \%)$ \\
\hline Outdoor use of pesticides & & \multicolumn{2}{|c|}{ Consumption of fruit juice } \\
\hline Yes & $57(24.9 \%)$ & Yes & $141(62.1 \%)$ \\
\hline No & $\begin{array}{l}172(75.1 \\
\%)\end{array}$ & No & $86(37.9 \%)$ \\
\hline $\begin{array}{l}\text { Indoor use of pesticides } \\
\text { Yes }\end{array}$ & $80(34.9 \%)$ & \multicolumn{2}{|l|}{ Drinking of water } \\
\hline No & $\begin{array}{l}149(65.1 \\
\%)\end{array}$ & bottled water & $114(49.8 \%)$ \\
\hline \multicolumn{2}{|c|}{$\begin{array}{l}\text { Recent outdoor activities (within } 2 \text { last } \\
\text { days) }\end{array}$} & \multicolumn{2}{|l|}{ Biting nails } \\
\hline Yes & $\begin{array}{l}209(91.3 \\
\%)\end{array}$ & Yes & $67(29.3 \%)$ \\
\hline No & $20(8.7 \%)$ & No & $162(70.7 \%)$ \\
\hline
\end{tabular}

monitored in urine, only metribuzin was detected in $10 \%$ of the samples, with concentrations ranging up to $1.68 \mu \mathrm{g} / 1(\mathrm{P} 95=0.34 \mu \mathrm{g} / \mathrm{l})$, propyzamide and 2,4-DB being found in very few samples (respectively 6 and 3 out of 257). Among metabolites, desethylterbutylazine, 4F-3PBA and DEDTP were also positively measured in very few samples (3.5 $\%, 2.2 \%$ and $6.3 \%$ repectively); while other non specific pyrethroid and OP metabolites were detected in a large majority of samples (from 28 to $100 \%$ ). TCPY, DEP, 3-PBA and t-DCCA were the most frequently detected and with the higher levels measured, ranging between < LOQ- $662 \mu \mathrm{g} / \mathrm{l}$.

The binary logistic regressions are detailed in Table 6 for metribuzin, THPI, DETP, DMDTP and c-DCCA according to the detection or non-detection rate, while the multivariate linear regression results are gathered in Table 7 for TCPY, DEP, DMTP, t-DCCA, and 3-PBA. The other pesticides or biomarkers showed very low detection frequencies (below $10 \%$ ) and were thus not included in the statistical analyses. The appellation "mixed origin" of vegetables included vegetables coming as well from supermarket, local producer, local market or private garden. The outdoor pesticide uses, the number of pets, the use of pet antiparasitics, and the proportion of organic fruits and vegetables in the diet $(>$ or $<$ than $50 \%$ ) did not impact significantly the pesticide urinary levels whatever the biomarkers considered.

\section{Discussion}

\subsection{Children's exposure assessment through ambient air}

Out of the 46 pesticides measured, 19 were detected in at least $10 \%$ of the air samples. The mean levels ranging from $<0.04$ to $2.37 \mathrm{ng} / \mathrm{m}^{3}$ seemed to be in the same magnitude order than those reported in France or in North America (ATMO-Poitou-Charentes, 2017; Coscollà et al., 2010, Kurt-Karakus et al., 2011; Majewski et al., 2014; Yao et al., 2006). As expected, the reference site (Habay) showed the lower number of pesticides detected and the lower levels measured in the air, while the highest air levels were measured in both agricultural and orchard sites (Gembloux and Oupeye respectively), with pesticide patterns consistent with the pesticide related activities. For instance, higher levels of captan usually intended for peer and apple tree protection were measured near orchards (in Oupeye), whereas herbicides dedicated among others to cereal and potato crop protection (i.e. pendimethalin, prosulfocarb and triallate) showed higher levels in Gembloux surrounded by cereal and beet fields.

Table 4

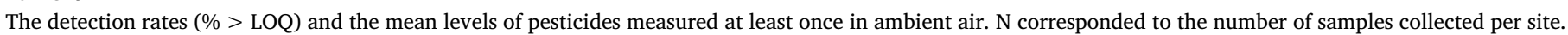
All other pesticides not reported in this table were never detected.

\begin{tabular}{|c|c|c|c|c|c|c|c|c|}
\hline Pesticides & LOQ & $\mathrm{N}>\mathrm{LOQ}$ & $\begin{array}{l}\text { Habay -reference site } \\
(\mathrm{N}=2)\end{array}$ & $\begin{array}{l}\text { Charleroi - urban } \\
\text { site }(\mathrm{N}=2)\end{array}$ & $\begin{array}{l}\text { Liege - urban site } \\
(\mathrm{N}=2)\end{array}$ & $\begin{array}{l}\text { Gembloux - agricultural } \\
\text { site }(\mathrm{N}=3)\end{array}$ & $\begin{array}{l}\text { Oupeye - agricultural } \\
\text { site }(\mathrm{N}=2)\end{array}$ & $\begin{array}{l}\text { Daily intake } \\
\text { (range) }\end{array}$ \\
\hline & $\left(\mathrm{ng} / \mathrm{m}^{3}\right)$ & $(\%)$ & $\left(\mathrm{ng} / \mathrm{m}^{3}\right)$ & $\left(\mathrm{ng} / \mathrm{m}^{3}\right)$ & $\left(\mathrm{ng} / \mathrm{m}^{3}\right)$ & $\left(\mathrm{ng} / \mathrm{m}^{3}\right)$ & $\left(\mathrm{ng} / \mathrm{m}^{3}\right)$ & (ng $/ \mathrm{kg} /$ day) \\
\hline $2,4 \mathrm{DB}$ & 0.04 & 22.2 & $<\mathrm{LOQ}$ & $<\mathrm{LOQ}$ & $<\mathrm{LOQ}$ & 0.25 & 0.56 & $0.09-0.21$ \\
\hline Benfluralin & 0.04 & 87.5 & $<\mathrm{LOQ}$ & 0.30 & 0.08 & 0.81 & 1.97 & $0.03-0.74$ \\
\hline Captan & 0.04 & 100.0 & 0.06 & 0.15 & 0.26 & 0.16 & 1.97 & $0.02-0.74$ \\
\hline Chlorothalonil & 0.10 & 100.0 & 0.26 & 1.58 & 0.27 & 0.95 & 1.03 & $0.10-0.60$ \\
\hline Difenoconazole & 0.04 & 11.1 & $<$ LOQ & $<$ LOQ & $<$ LOQ & $<$ LOQ & 0.06 & NA-0.02 \\
\hline Dimethenamid-P & 0.04 & 77.8 & $<\mathrm{LOQ}$ & 0.38 & 0.12 & 0.78 & 1.36 & $0.05-0.51$ \\
\hline Epoxyconazole & 0.04 & 44.4 & $<\mathrm{LOQ}$ & 0.07 & $<$ LOQ & 0.06 & 0.04 & $0.01-0.03$ \\
\hline Ethofumesate & 0.10 & 66.7 & $<\mathrm{LOQ}$ & 0.32 & 0.12 & 0.53 & 0.25 & $0.04-0.20$ \\
\hline Kresoxim-methyl & 0.04 & 11.1 & $<\mathrm{LOQ}$ & $<$ LOQ & $<$ LOQ & $<$ LOQ & 0.08 & NA -0.03 \\
\hline Linuron & 0.04 & 44.4 & $<\mathrm{LOQ}$ & 0.12 & $<\mathrm{LOQ}$ & 0.19 & $<\mathrm{LOQ}$ & $0.05-0.07$ \\
\hline Pendimethalin & 0.10 & 88.9 & 0.12 & 0.86 & 0.34 & 1.70 & 0.39 & $0.04-0.64$ \\
\hline Propiconazole & 0.04 & 11.1 & $<$ LOQ & 0.06 & $<$ LOQ & $<$ LOQ & $<$ LOQ & NA -0.02 \\
\hline Propyzamide & 0.10 & 22.2 & $<\mathrm{LOQ}$ & $<$ LOQ & $<$ LOQ & 0.15 & $<$ LOQ & NA-0.06 \\
\hline Prosulfocarb & 0.10 & 77.8 & $<$ LOQ & 0.59 & 0.28 & 1.45 & 0.11 & $0.04-0.55$ \\
\hline S-metolachlor & 0.04 & 88.9 & 0.05 & 0.62 & 0.22 & 1.67 & 2.37 & $0.02-0.89$ \\
\hline Spiroxamine & 0.04 & 11.1 & $<$ LOQ & $<$ LOQ & $<\mathrm{LOQ}$ & $<$ LOQ & 0.05 & NA - 0.02 \\
\hline Tebuconazole & 0.04 & 33.3 & $<\mathrm{LOQ}$ & 0.09 & $<$ LOQ & 0.06 & $<$ LOQ & $0.02-0.03$ \\
\hline Terbuthylazine & 0.04 & 77.8 & $<\mathrm{LOQ}$ & 0.24 & 0.07 & 0.23 & 0.25 & $0.02-0.09$ \\
\hline Triallate & 0.10 & 66.7 & $<\mathrm{LOQ}$ & 0.68 & 0.19 & 1.15 & 0.34 & $0.07-0.43$ \\
\hline
\end{tabular}


Table 5

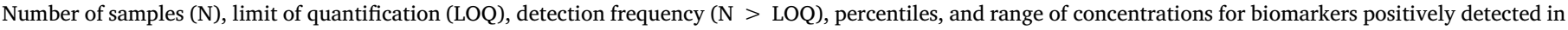
urine.

\begin{tabular}{|c|c|c|c|c|c|c|c|c|}
\hline & $\mathrm{N}$ & $\begin{array}{l}\text { LOQ } \\
(\mu \mathrm{g} / 1)\end{array}$ & $\begin{array}{l}\mathrm{N}>\mathrm{LOQ} \\
(\%)\end{array}$ & $\begin{array}{l}\text { P25 } \\
(\mu g / l)\end{array}$ & $\begin{array}{l}\text { P50 } \\
(\mu g / 1)\end{array}$ & $\begin{array}{l}\text { P75 } \\
(\mu \mathrm{g} / \mathrm{l})\end{array}$ & $\begin{array}{l}\text { P95 } \\
(\mu g / 1)\end{array}$ & $\begin{array}{l}\text { Min-max } \\
(\mu \mathrm{g} / 1)\end{array}$ \\
\hline \multicolumn{9}{|c|}{ Parent pesticides or specific metabolites } \\
\hline Metribuzin & 257 & 0.20 & 10.1 & $<\mathrm{LOQ}$ & $<\mathrm{LOQ}$ & $<\mathrm{LOQ}$ & 0.34 & $<$ LOQ-1.68 \\
\hline Propyzamide & 257 & 0.05 & 2.3 & $<$ LOQ & $<$ LOQ & $<$ LOQ & $<$ LOQ & $<$ LOQ-0.05 \\
\hline $2,4-\mathrm{DB}$ & 257 & 0.15 & 1.2 & $<\mathrm{LOQ}$ & $<\mathrm{LOQ}$ & $<\mathrm{LOQ}$ & $<\mathrm{LOQ}$ & $<$ LOQ-1.69 \\
\hline Desethylterbutylazine & 257 & 0.05 & 3.5 & $<\mathrm{LOQ}$ & $<\mathrm{LOQ}$ & $<$ LOQ & $<$ LOQ & $<$ LOQ-0.94 \\
\hline THPI & 220 & 0.20 & 23.5 & $<$ LOQ & $<$ LOQ & $<$ LOQ & 0.65 & $<$ LOQ-4.13 \\
\hline TCPY & 229 & 0.08 & 100.0 & 2.33 & 3.87 & 6.09 & 12.12 & $0.36-38.96$ \\
\hline \multicolumn{9}{|l|}{ Pyrethroid metabolites } \\
\hline 3-PBA & 229 & 0.09 & 99.6 & 0.51 & 0.98 & 1.99 & 5.33 & $<$ LOQ-311.1 \\
\hline c-DCCA & 206 & 0.50 & 40.3 & $<$ LOQ & $<$ LOQ & 0.75 & 2.01 & $<$ LOQ-55.6 \\
\hline t-DCCA & 220 & 0.15 & 93.2 & 0.27 & 0.66 & 1.31 & 4.29 & $<$ LOQ-501.3 \\
\hline 4-F-3-PBA & 229 & 0.11 & 2.2 & $<$ LOQ & $<$ LOQ & $<$ LOQ & $<$ LOQ & $<$ LOQ-1.74 \\
\hline \multicolumn{9}{|c|}{ Organophosphorous metabolites } \\
\hline DMTP & 216 & 0.50 & 64.8 & $<\mathrm{LOQ}$ & 1.01 & 3.55 & 13.72 & < LOQ-231.3 \\
\hline DMDTP & 240 & 0.50 & 27.9 & $<\mathrm{LOQ}$ & $<$ LOQ & 0.91 & 1.31 & < LOQ-9.91 \\
\hline DEP & 240 & 0.50 & 73.3 & $<\mathrm{LOQ}$ & 1.80 & 4.92 & 29.97 & < LOQ-661.8 \\
\hline DETP & 240 & 0.50 & 49.2 & $<\mathrm{LOQ}$ & $<$ LOQ & 1.11 & 3.50 & < LOQ-4.64 \\
\hline DEDTP & 240 & 0.50 & 6.3 & $<$ LOQ & $<$ LOQ & $<$ LOQ & 0.59 & $<$ LOQ-2.10 \\
\hline
\end{tabular}

The exposure of the children through inhalation was assessed by estimating the inhalation daily intake doses (DI). The $\mathrm{DI}_{\text {inh }}$ ranged from 0.02 to $0.89 \mathrm{ng} / \mathrm{kg} / \mathrm{d}$, according to the pesticide and the location. These values are far below the acceptable daily intake (ADI) set by the European Commission varying between 0.005 and $0.1 \mathrm{mg} / \mathrm{kg} / \mathrm{d}$ according to the pesticide, but also well below the daily intake estimated for OP pesticides based on HBM data, ranging from $0.04-30 \mu \mathrm{g} / \mathrm{kg} /$ day for children depending on the OP pesticide considered (Katsikantami et al., 2019), or below the DI estimated through diet studies for instance between $0.001-2.5 \mu \mathrm{g} / \mathrm{kg} / \mathrm{d}$ for Spanish adult women, Moldovan or Hong Kong adults for a wide range of different pesticides (Iñigo-Nuñez et al., 2010; Sircu et al., 2015; Wong et al., 2014).

\subsection{Children's exposure assessment through internal dose}

Metribuzin was the only parent pesticide positively detected in the urine samples (10\%). To our knowledge, this is the first time that its presence was reported in the urine of individuals either from the general population or from occupationally exposed individuals. Data on the toxicokinetic of metribuzin are inexistent in human and scarce on animals, with mercapturic acid derivatives reported as main metabolites eliminated in the urine of treated rats and mice (Bleeke and Casida, 1984). For other triazines such like atrazine, the unmodified parent pesticide was demonstrated to represent only $2 \%$ of the excreted doses in urine of mammals (Maroni et al., 2000). Therefore the results of the present study could be worrying because could suggest sufficiently high exposure to induce detectable urinary levels of the parent compound. On the other hand, THPI, which was usually considered as biomarker for the monitoring of captan exposure (Berthet et al., 2012; HerediaOrtiz and Bouchard, 2012) was detected in $23.5 \%$ of the urine samples with levels up to $4.13 \mu \mathrm{g} / \mathrm{l}$, similarly to levels reported in UK adults and children living near orchards (Galea et al., 2015).

3-PBA which was a common metabolite to numerous pyrethroids was found in 228 out of the 229 urine samples analyzed, while t-DCCA was detected in $93 \%$ of the samples. Moreover, at least one OP metabolite was detected in all urine samples, highlighting the ubiquitous exposure of children to OP and pyrethroid pesticides. Compared to previous studied carried out worldwide (Table 8), the levels of pyrethroid metabolites measured in the urine of our Belgian children seemed higher than those reported for children from Germany (Becker et al., 2006), Spain (Roca et al., 2014), France (Glorennec et al., 2017), Canada (Oulhote and Bouchard, 2013) or US (CDC, 2019). The TCPY levels measured were similar to those reported for Spanish children
(Roca et al., 2014), but roughly twice higher than in US children from the 2009-2010 NHANES cycle (CDC, 2019). Conversely, the levels of DAP were lower than those reported in the urine of children living in neighboring countries such like in Germany, Spain or France, and even lower than those reported in Canadian or US children (Table 8) although higher OP exposure was usually observed in Europe compared to America (Kavvalakis and Tsatsakis, 2012). Even more surprisingly, DAP levels seemed substantially lower in children living in Wallonia than toddlers residing in Flanders (Schoeters et al., 2011) suggesting different exposure levels to pesticides between the North and South of the country. Because the environmental policy is a regional competence in Belgium, the implementation of pesticide regulations was different in the 3 regions (Brussels, Flanders and Wallonia) potentially resulting in regional specific exposure to pesticides.

\subsection{Contribution of inhalation to the global exposure}

To study the contribution of inhalation to the global exposure, the pesticides frequently detected in air was firstly compared to the pesticides (unchanged or urinary biomarkers) positively measured in urine. The most abundant and frequently detected pesticides in the air such like benfluralin, dimethenamid-P, ethofumesate, pendimethalin, prosulfocarb, s-metolachlor or triallate (positively detected in $66.7 \%-88.9 \%$ of air samples), were not detected in the urine of children as parent compound. On the other hand, desethylterbuthylazine, a commonly accepted metabolite of terbuthylazine (Mercadante et al., 2013) was sporadically detected in urine (in $3.5 \%$ of urine samples) although terbuthylazine was found in all air samples except those from the reference site. Furthermore, metribuzin which was detected in $10 \%$ of the urine samples was never detected in air. These observations would argue that the contribution of air inhalation to the global exposure to pesticides was too low to induce measurable levels of urinary biomarkers, even if some parent pesticides were likely not the best biomarkers for the monitoring of the environmental exposure. Moreover, the specific and unspecific urinary metabolites of OP and pyrethroids were frequently detected at sometimes high concentrations whereas the corresponding parents monitored in air were never or sparsely detected (chlorpyrifos-ethyl was found in $22 \%$ of air samples, while dimethoate, cyhalothrin, cypermethrin or deltamethrin were never detected). And finally, levels and detection frequencies of THPI were significantly lower in the urine of children living in Oupeye where the highest captan concentrations were measured in the air. Thus for captan, pyrethroids and OP, inhalation would poorly contribute to the 


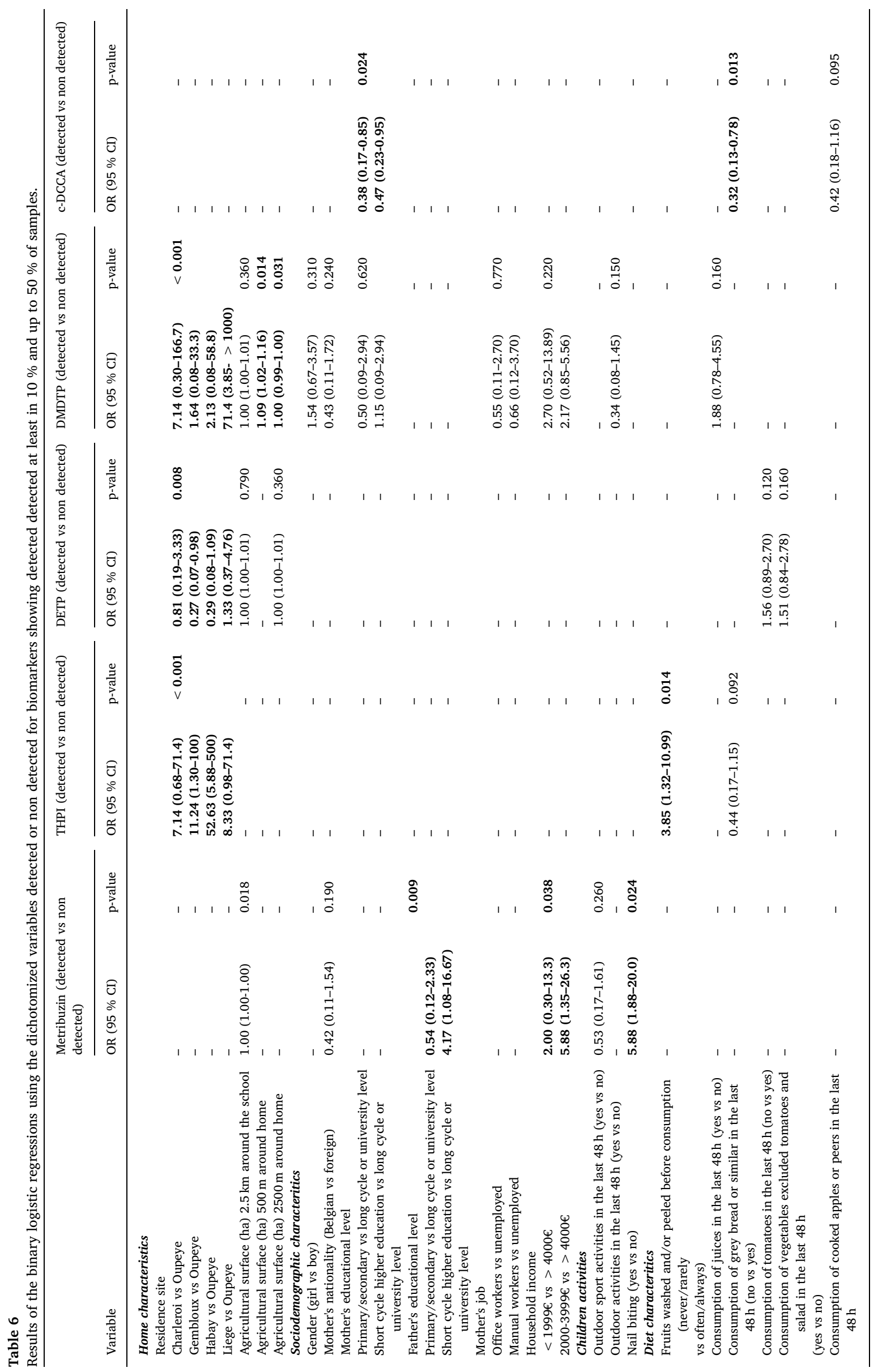




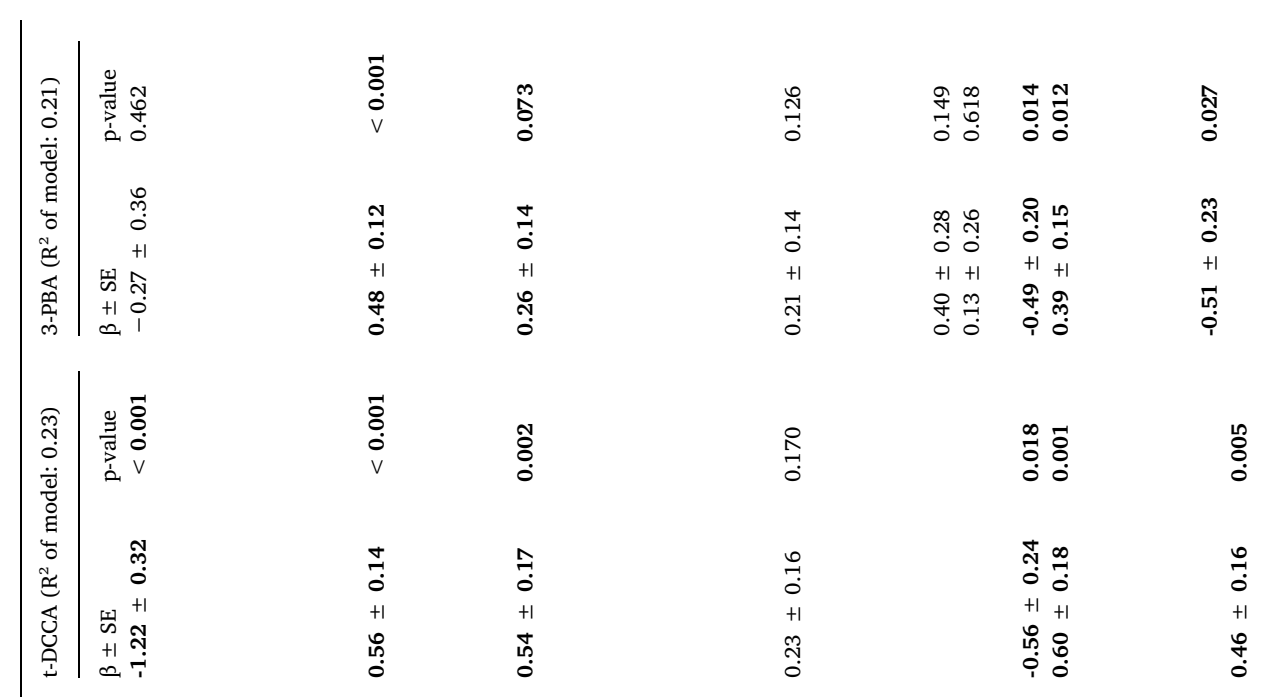

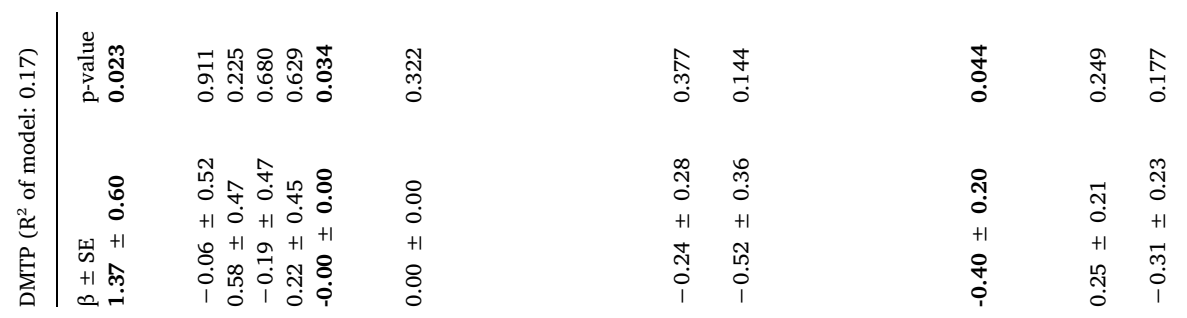

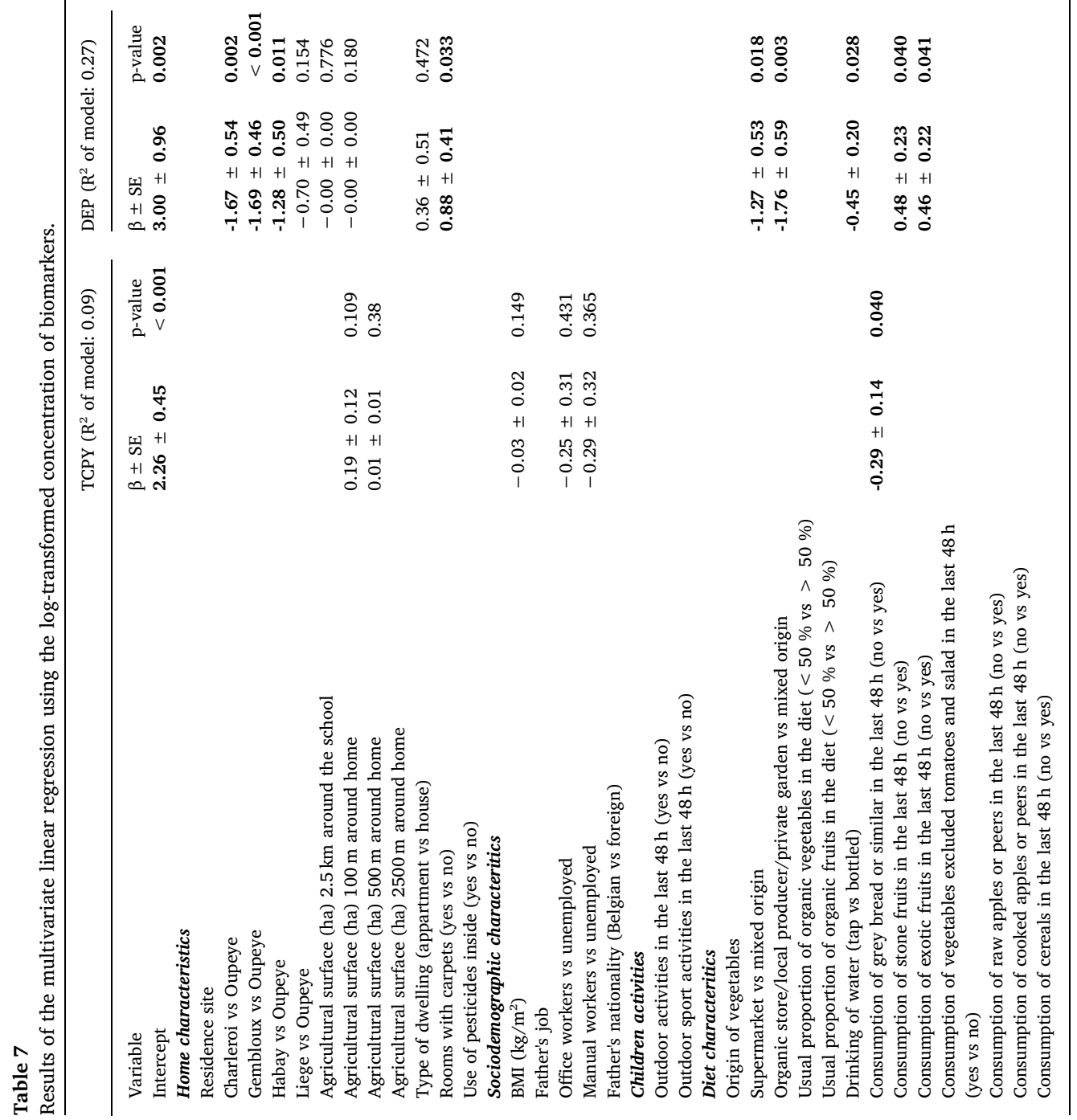


Table 8

P50 (in $\mu \mathrm{g} / \mathrm{L}$ ) reported from worldwide HBM studies focused on children.

\begin{tabular}{|c|c|c|c|c|c|c|c|c|c|}
\hline Years of collection & $\begin{array}{l}\text { Belgium } \\
2016\end{array}$ & $\begin{array}{l}\text { Belgium } \\
\text { 2008-2009 }\end{array}$ & $\begin{array}{l}\text { Germany } \\
2001-2002\end{array}$ & $\begin{array}{l}\text { Spain } \\
2009-2010\end{array}$ & $\begin{array}{l}\text { France } \\
2009-2012\end{array}$ & $\begin{array}{l}\text { Norway } \\
2012\end{array}$ & $\begin{array}{l}\text { Canada } \\
2007-2009\end{array}$ & $\begin{array}{l}\text { US } \\
2007-2008\end{array}$ & $\begin{array}{l}\text { US } \\
2009-2010\end{array}$ \\
\hline $\mathrm{N}$ & $206-240$ & 210 & 369 & 125 & 245 & 54 & $981-1036$ & 385 & 386 \\
\hline Age (yrs) & $9-12$ yrs & $14-15$ yrs & $0-17$ yrs & $6-11$ yrs & 6 yrs & $6-12$ yrs & $6-11$ yrs & $6-11$ yrs & $6-11$ yrs \\
\hline Cohort & Present study & FLEHS II & GeRES IV & from Valencia & PELAGIE & from Oslo & CHMS & NHANES & NHANES \\
\hline References & Present study & Schoeters $^{\text {a }}$ & Becker $^{\mathrm{b}}$ & $\operatorname{Roca}^{\mathrm{c}}$ & Glorennec $^{\mathrm{d}}$ & Cequier ${ }^{\mathrm{e}}$ & Oulhote $\mathrm{f}^{\mathrm{f}}$ & $\mathrm{CDC}^{\mathrm{g}}$ & $\mathrm{CDC}^{\mathrm{g}}$ \\
\hline \multicolumn{10}{|c|}{ Organophosphorus metabolites $(\mu \mathrm{g} / \mathrm{l}$ ) } \\
\hline DMTP & 1.0 & 5.8 & 7.9 & $<0.4$ & - & 5.3 & 2.5 & 3.5 & - \\
\hline DMDTP & $<0.5$ & $<1$ & $<0.1$ & $<0.4$ & - & $<0.6$ & $<0.3$ & $<0.5$ & - \\
\hline DEP & 1.8 & 2.5 & 3.3 & 2.3 & - & 3.8 & 3.3 & $<0.4$ & - \\
\hline DETP & $<0.5$ & $<1$ & 1.1 & $<0.4$ & - & 0.4 & $<0.6$ & $<0.6$ & - \\
\hline DEDTP & $<0.5$ & $<2$ & $<0.1$ & $<0.4$ & - & $<0.1$ & $<0.3$ & $<0.4$ & - \\
\hline TCPY & 3.9 & - & - & 3.4 & - & - & - & - & 1.5 \\
\hline \multicolumn{10}{|c|}{ Pyrethroid metabolites $(\mu \mathrm{g} / \mathrm{l})$} \\
\hline 3-PBA & 1.0 & - & 0.3 & $<0.8$ & 0.02 & - & 0.2 & - & 0.5 \\
\hline c-DCCA & $<0.5$ & - & 0.1 & $<0.8$ & 0.09 & - & 0.1 & - & - \\
\hline t-DCCA & 0.7 & - & 0.2 & $<0.4$ & 0.22 & - & $<0.15$ & - & $<0.6$ \\
\hline 4-F-3-PBA & $<0.1$ & - & $<0.1$ & $<0.2$ & $<0.003$ & - & 0.2 & - & $<0.1$ \\
\hline
\end{tabular}

a Schoeters et al., 2011.

b Becker et al., 2006.

c Roca et al., 2014.

d Glorennec et al., 2017.

e Cequier et al., 2017.

f Oulhote and Bouchard, 2013.

g CDC, 2019.

global exposure. Similar conclusion was reported by Galea et al. (2015) who did not observe, during some captan spray events, increased levels of THPI in the urine of UK adults and children.

\subsection{Predictors of exposure}

Biting nails, household income, and father's educational level were highlighted by the statistical regression as predictors of exposure for metribuzin, while living in Oupeye and often washing or peeling fruits before consumption seemed to statistically decrease the detection frequencies of THPI in the children's urine. Since metribuzin was not detected in the air whatever the site considered, other sources of exposure than outdoor air should occur. Because metribuzin was not found in any of the 3873 food samples collected during the Belgian's pesticide monitoring program in 2014 (FASFC, 2019), and very rarely measured above $2 \mathrm{ng} / \mathrm{l}$ in drinking water during the yearly internal controls recorded by the Walloon Region (unpublished data), neither food intake nor drinking water seemed to be a significant pathway of exposure. On the other hand, metribuzin was statistically more often detected in the urine of children who used to bite their nails. This could suggest an intake through hand-to-mouth behavior, and thus a contamination of either domestic dust or outdoor soil particles. Note that the number of positive samples was quite low thus questioning the power of the statistical model.

For OP and pyrethroid metabolites, the main predictors of exposure brought out by the statistical analyses were the consumption of grey bread, the indoor use of pesticides (for pyrethroids), and the presence of carpets at home (for DEP only), confirming for this latter that indoor dust contamination could also represent a non negligible pathway of OP pesticide exposure (Shalat et al., 2003). Unexpectedly, all food items recently eaten other than grey bread were not associated with increasing levels of OP or pyrethroid metabolites although some parents, like chlorpryrifos, have been positively detected in some Belgian food, such as in infusions, fruits or vegetables (FASFC, 2019). Moreover, the proportion of organic fruits and vegetables usually consumed seemed to not affect the levels of urinary pesticide biomarkers, but one should keep in mind that a large majority of children (85-87 \%) reported to usually eat less than $50 \%$ of organic food thus leveled the potential impact of such diet in the present study. The main finding is probably the very low $\mathrm{R}^{2}$ obtained for all statistical regressions meaning that the main sources of exposure were missed and/or too many covariates were included in each model. Nevertheless, the increased urinary levels of tDCCA and 3-PBA with the indoor use of pesticides are consistent with other studies carried out in France (Glorennec et al., 2017), Canada (Oulhote and Bouchard, 2013), United States (Bradman et al., 2015; Lu et al., 2006b) or China (Wang et al., 2016), questioning the importance of the diet contribution to pyrethroid exposure compared to indoor residential exposure for children (Trunnelle et al., 2014).

Some strange associations between urinary biomarkers and the consumption of food were quite difficult to interpret, such like the negative associations with the consumption of exotic or stone fruits, of cereals or juice, or the drinking of tap water. Similarly, the different detection frequencies of DETP and DMDTP respectively for children living in Gembloux and in Liege compared to Oupeye remained unexplained. All these statistically significances would likely due to confounding factors or to hazardous.

\subsection{Strengths and limitations of the study}

This study was the first assessing the Belgian children's exposure to a wide range of currently used pesticides through simultaneous human biomonitoring and ambient air analysis. Its strengths come from the concomitant analyses of environmental and biological samples, the fair number of participants, their representativeness in terms of gender and age, the high quality and reliability of the produced analytical data, and the use of statistical models using multivariate regressions incorporating among others answers to a $48 \mathrm{~h}$ recall questionnaire. Nevertheless this study also suffers from some limitations. Firstly, urinary levels of pesticide metabolites such like DAP or pyrethroid metabolites have been demonstrated to be subject to high within-individual variability resulting in poor reliability of a single spot urine sample to characterize individual child exposure (Attfield et al., 2014; Cequier et al., 2017; Egeghy et al., 2011; Griffith et al., 2011; Morgan, 2012). Moreover, we tried to study the potential impact of pesticide in air on urinary biomarkers although the levels in air were averaged over 2 weeks while the urinary biomarkers used to reflect the exposure from few hours to one day. Secondly, the recruitment strategy could induce a bias in the representativeness of the studied population because 
voluntary based. The results of the statistical analysis should also be cautiously interpreted because of the high amount of information gathered and introduced in the regression models likely resulting in some spurious associations (Riederer et al., 2008), because the collection of these information was driven by a priori assumptions on sources of exposure and thus could lead to the miss of some confounding factors yet unknown, and finally because a wide variety of answers were collected from the $48 \mathrm{~h}$ recall questionnaire compelling us to arbitrarily group some food items into more general categories. Thirdly the metabolite levels measured would not only reflect the exposure to the parent pesticides but also the exposure to environmental degradation products generally less toxic (Barr, 2008; Chen et al., 2012; Sudakin and Stone, 2011), thus could result in an overestimation of the exposure risk assessment. And finally, the most relevant limitation would likely be the attempt to assess pesticide exposure by measuring some unmetabolised compounds which would probably not be the best biomarker.

\section{Conclusion}

This study provides the first data on the exposure to several currently used pesticides of Belgian children living in Wallonia. Concomitant measures of a wide range of pesticides in ambient air and urine were carried out to assess the internal dose of children aged from 9 to 12 years old, to study the contribution of inhalation to the overall exposure, and to identify some predictors of exposure for these children. Despite several limitations related to HBM studies, the nature of the samples and the biomarkers monitored, the obtained results allowed to highlight a ubiquitous exposure to pyrethroid and OP pesticides for Belgian children, a probable negligible contribution of inhalation compared to other routes of exposure, the effect of consuming grey bread, having carpets at home and using pesticides inside the house on the children's internal dose of some pesticides. However, the coefficients of determination of the statistical regressions were small, suggesting that the main sources of exposure were not taken into account and should therefore be still investigated.

\section{Ethical approval}

This protocol was approved by the Hospital Faculty Ethics Committee of the University of Liege (B707201627617).

\section{Declaration of Competing Interest}

The authors declare that they have no known competing financial interests or personal relationships that could have appeared to influence the work reported in this paper

\section{Acknowledgments}

This study was financially supported by the ISSeP's Funds using Moerman mechanism (article 275/3, § 3, of the Belgian Income Tax Code 92).

\section{Appendix A. Supplementary data}

Supplementary material related to this article can be found, in the online version, at doi:https://doi.org/10.1016/j.toxlet.2020.04.020.

Details on materials and methods for air and urine analyses, including extraction, chromatographic conditions and mass spec parameters.

\section{References}

Angerer, J., Ewers, U., Wilhelm, M., 2007. Human biomonitoring: state of the art. Int. J. Hyg. Environ. Health 210 (3-4), 201-228. https://doi.org/10.1016/j.ijheh.2007.01.
024.

ATMO-Poitou-Charentes, 2017. Mesure des pesticides dans l'air - Campagne 2016 Poitiers (86), Saint Saturnin (16), La Rochelle (17), Saint Junien (87) - Février Décembre 2016. Report available on https://www.atmo-nouvelleaquitaine.org/sites/ aq/files/atoms/files/rapportatmona_pest_int_16_001_pest_16_versionfinale_2017-0606.pdf. Last accessed on September 18, 2019.

Attfield, K.R., Hughes, M.D., Spengler, J.D., Lu, C., 2014. Within- and between-child variation in repeated urinary pesticide metabolite measurements over a 1-Year period. Environ. Health Perspect. 122, 201-206. https://doi.org/10.1289/ehp. 1306737.

Barr, D.B., 2008. Biomonitoring of exposure to pesticides. J. Chem. Health Saf. 15, 20-29. https://doi.org/10.1016/j.jchas.2008.07.001.

Becker, K., Seiwert, M., Angerer, J., Kolossa-Gehring, M., Hoppe, H.-W., Ball, M., Schulz, C., Thumulla, J., Seifert, B., 2006. GerES IV pilot study: assessment of the exposure of german children to organophosphorus and pyrethroid pesticides. Int. J. Hyg. Environ. Health 209, 221-233. https://doi.org/10.1016/j.ijheh.2005.12.002.

Berthet, A., Bouchard, M., Vernez, D., 2012. Toxicokinetics of Captan and folpet biomarkers in dermally exposed volunteers. J. Appl. Toxicol. 32, 202-209. https://doi. org/10.1002/jat.1659.

Bleeke, M., Casida, J.E., 1984. Metribuzin metabolites in mammals and liver microsomal oxidase systems: identification, synthesis, and reactions. J. Agric. Food Chem. 32, 749-755.

Bradman, A., Whyatt, R.M., 2005. Characterizing exposures to nonpersistent pesticides during pregnancy and early childhood in the national children's study: a review of monitoring and measurement methodologies. Environ. Health Perspect. 113, 1092-1099. https://doi.org/10.1289/ehp.7769.

Bradman, A., Quirós-Alcalá, L., Castorina, R., Schall, R.A., Camacho, J., Holland, N.T., Barr, D.B., Eskenazi, B., 2015. Effect of organic diet intervention on pesticide exposures in young children living in low-income urban and agricultural communities. Environ. Health Perspect. 123, 1086-1093. https://doi.org/10.1289/ehp.1408660.

CDC (Center for Disease Control and Prevention), 2019. Fourth National Report on Human Exposure to Environmental Chemicals, Atlanta. Available online: http:// www.cdc.gov/exposurereport/pdf/fourthreport.pdf. Last accessed on September 18.

Cequier, E., Sakhi, A.K., Haug, L.S., Thomsen, C., 2017. Exposure to organophosphorus pesticides in norwegian mothers and their children: diurnal variability in concentrations of their biomarkers and associations with food consumption. Sci. Tot. Environ. 590-591, 655-662. https://doi.org/10.1016/j.scitotenv.2017.03.017.

Chen, L., Zhao, T., Pan, C., Ross, J.H., Krieger, R.I., 2012. Preformed biomarkers including dialkylphosphates (DAPs) in produce may confound biomonitoring in pesticide exposure and risk assessment. J. Agric. Food Chem. 60, 9342-9351. https://doi.org/10. 1021/jf303116p.

Coscollà, C., Colin, P., Yahyaoui, A., Petrique, O., Yusà, V., Mellouki, A., Pastord, A., 2010. Occurrence of currently used pesticides in ambient air of Centre Region (France). Atmos. Environ. 44, 3915-3925. https://doi.org/10.1016/j.atmosenv. 2010.07.014.

Curl, C.L., Fenske, R.A., Kissel, J.C., Shirai, J.H., Moate, T.F., Griffith, W., Coronado, G., Thompson, B., 2002. Evaluation of Take-Home Organophosphorus Pesticide Exposure among Agricultural Workers and Their Children. Environ. Health Perspect. 110 (12), a787-a792. https://doi.org/10.1289/ehp.021100787.

Dubois, N., Paccou, A.P., De Backer, B.G., Charlier, C.J., 2012. Validation of the quantitative determination of tetrahydrocannabinol and its two major metabolites in plasma by ultra high-performance liquid chromatography-tandem mass spectrometry according to the total error approach. J. Anal. Toxicol. 36, 25-29. https://doi.org/10. 1093/jat/bkr009.

Egeghy, P.P., Cohen Hubal, E.A., Tulve, N.S., Melnyk, L.J., Morgan, M.K., Fortmann, R.C., Sheldon, L.S., 2011. Review of pesticide urinary biomarker measurements from selected US EPA children's observational exposure studies. Int. J. Environ. Res. Public Health 8, 1727-1754. https://doi.org/10.3390/ijerph8051727.

FAOSTAT. 2019. Data. http://www.fao.org/faostat/en/\#data. Last accessed on September 18, 2019.

FASFC (Federal Agency for the Safety of the Food Chain), 2019. Controls of Pesticide Residues in Food and Feed - Belgium 2014. National Summary Report. Available on http://www.afsca.be/publicationsthematiques/_documents/2015_RapportEFSAFinal.pdf. Last accessed on September 18.

Galea, K.S., MacCalman, L., Jones, K., Cocker, J., Teedon, P., Cherrie, J.W., van Tongeren, M., 2015. Urinary Biomarker Concentrations of Captan, Chlormequat, Chlorpyrifos and Cypermethrin in UK Adults and Children Living near Agricultural Land. J. Expo. Sci. Environ. Epidemiol. 25, 623-631. https://doi.org/10.1038/jes.2015.54.

Giusti, A., Pirard, C., Charlier, C., Petit, J.C.J., Crevecoeur, S., Remy, S., 2018. Selection and ranking method for currently used pesticides (CUPs) monitoring in ambient air. Air Qual. Atmos. Health 11, 385-396. https://doi.org/10.1007/s11869-017-0516-6.

Glorennec, P., Serrano, T., Fravallo, M., Warembourg, C., Monfort, C., Cordier, S., Viel, J.F., Le Gléau, F., Le Bot, B., Chevrier, C., 2017. Determinants of children's exposure to pyrethroid insecticides in Western France. Environ. Int. 104, 76-82. https://doi.org/ 10.1016/j.envint.2017.04.007.

Göen, T., Schmidt, L., Lichtensteiger, W., Schlumpf, M., 2017. Efficiency control of dietary pesticide intake reduction by human biomonitoring. Int. J. Hyg. Environ. Health 220 (2), 254-260. https://doi.org/10.1016/j.ijheh.2016.11.008.

Griffith, W., Curl, C.L., Fenske, R.A., Lu, C.A., Vigoren, E.M., Faustman, E.M., 2011 Organophosphate pesticide metabolite levels in pre-school children in an agricultural community: within- and between-child variability in a longitudinal study. Environ. Res. 111, 751-756. https://doi.org/10.1016/j.envres.2011.05.008.

Heredia-Ortiz, R., Bouchard, M., 2012. Toxicokinetic modeling of captan fungicide and its tetrahydrophthalimide biomarker of exposure in humans. Toxicol. Lett. 213, 27-34. https://doi.org/10.1016/j.toxlet.2011.09.023.

Holme, F., Thompson, B., Holte, S., Vigoren, E.M., Espinoza, N., Ulrich, A., Griffith, W., 
Faustman, E.M., 2016. The role of diet in children's exposure to organophosphate pesticides. Environ. Res. 147, 133-140. https://doi.org/10.1016/j.envres.2016.02. 003.

Hornung, R.W., Reed, L.D., 1990. Estimation of average concentration in the presence of non detectable values. Appl. Occup. Environ. Hyg. 5, 46-51. https://doi.org/10. 1080/1047322X.1990.10389587.

Hubert, P., Nguyen-Huu, J.J., Boulanger, B., Chapuzet, E., Chiap, P., Cohen, N., Compagnon, P.-A., Dewe, W., Feinberg, M., Lallier, M., Laurentie, M., Mercier, N., Muzard, G., Nivet, C., Valat, L., Rozet, E., 2007. Harmonization of strategies for the validation of quantitative analytical procedures: a SFSTP proposal e Part II. J. Pharmaceut. Biomed. Anal. 45, 70e81. https://doi.org/10.1016/j.jpba.2007.06.013.

Iñigo-Nuñez, S., Herreros, M.A., Encinas, T., Gonzalez-Bulnes, A., 2010. Estimated daily intake of pesticides and xenoestrogenic exposure by fruit consumption in the female population from a Mediterranean country (Spain). Food Control 21, 471-477. https://doi.org/10.1016/j.foodcont.2009.07.009.

Joas, R., Casteleyn, L., Biot, P., Kolossa-Gehring, M., Castano, A., Angerer, J., Schoeters, G., Sepai, O., Knudsen, L.E., Joas, A., et al., 2012. Harmonised human biomonitoring in Europe: activities towards an EU HBM framework. Int. J. Hyg. Environ. Health 215 (2), 172-175. https://doi.org/10.1016/j.ijheh.2011.08.010.

Katsikantami, I., Colosio, C., Alegakis, A., Tzatzarakis, M.N., Vakonaki, E., Rizos, A.K., Sarigiannis, D.A., Tsatsakis, A.M., 2019. Estimation of daily intake and risk assessment of organophosphorus pesticides based on biomonitoring data - the internal exposure approach. Food Chem. Toxicol. 123, 57-71. https://doi.org/10.1016/j.fct. 2018.10.047.

Kavvalakis, M.P., Tsatsakis, A.M., 2012. The atlas of dialkylphosphates; assessment of cumulative human organophosphorus pesticides' exposure. Forensic Sci. Int. 218, 111-122. https://doi.org/10.1016/j.forsciint.2011.10.019.

Koch, D., Lu, C., Fisker-Andersen, J., Jolley, L., Fenske, R.A., 2002. Temporal association of children's pesticide exposure and agricultural spraying: report of a longitudinal biological monitoring study. Environ. Health Perspect. 110 (8), 829-833. https://doi. org/10.1289/ehp.02110829.

Kurt-Karakus, P.B., Teixeira, C., Small, J., Muir, D., Bidleman, T.F., 2011. Current-use pesticides in inland lake waters, precipitation, and air from Ontario, Canada. Environ. Toxicol. Chem. 30, 1539-1548. https://doi.org/10.1002/etc.545.

Lenoir, J.S., McConnell, L.L., Fellers, G.M., Cahill, T.M., Seiber, J.N., 1999. Summertime transport of current-use pesticides from California's Central Valley to the Sierra Nevada Mountain Range, USA. Environ. Toxicol. Chem. 18, 2715-2722. https://doi. org $/ 10.1002 /$ etc. 5620181210 .

Lu, C., Toepel, K., Irish, R., Fenske, R.A., Barr, D.B., Bravo, R., 2006a. Organic diets significantly lower children's dietary exposure to organophosphorus pesticides. Environ. Health Perspect. 114, 260-263. https://doi.org/10.1289/ehp.8418.

Lu, C., Barr, D.B., Pearson, M., Bartell, S., Bravo, R., 2006b. A longitudinal approach to assessing urban and suburban children's exposure to pyrethroid pesticides. Environ. Health Perspect. 114, 1419-1423. https://doi.org/10.1289/ehp.9043.

Mai, C., Theobald, N., Lammel, G., Hühnerfuss, H., 2013. Spatial, seasonal and vertical distributions of currently-used pesticides in the marine boundary layer of the North Sea. Atmos. Environ. 75, 92-102. https://doi.org/10.1016/j.atmosenv.2013.04.027.

Majewski, M.S., Coupe, R.H., Foreman, W.T., Capel, P.D., 2014. Pesticides in Mississippi air and rain: a comparison between 1995 and 2007. Env. Toxicol. Chem. 33, 1283-1293. https://doi.org/10.1002/etc.2550.

Maroni, M., Colosio, C., Ferioli, A., Fait, A., 2000. Chapter 9 : miscellaneous pesticides. Toxicol. 143, 97-102.

Mercadante, R., Polledri, E., Bertazzi, P.A., Fustinoni, S., 2013. Biomonitoring short- and long-term exposure to the herbicide terbuthylazine in agriculture workers and in the general population using urine and hair specimens. Environ. Int. 60, 42-47. https:// doi.org/10.1016/j.envint.2013.07.016.

Morgan, M.K., 2012. Children's exposures to pyrethroid insecticides at home: a review of data collected in published exposure measurement studies conducted in the United States. Int. J. Environ. Res. Public Health 9, 2964-2985. https://doi.org/10.3390/ ijerph9082964.

Needham, L.L., Özkaynak, H., Whyatt, R.M., Barr, D.B., Wang, R.Y., Naeher, L., Akland, G., Bahadori, T., Bradman, A., Fortmann, R, et al, 2005. Exposure assessment in the national children's study: introduction. Environ. Health Perspect. 113, 1076-1082. https://doi.org/10.1289/ehp.7613.
Oulhote, Y., Bouchard, M.F., 2013. Urinary metabolites of organophosphate and pyrethroid pesticides and behavioral problems in canadian children. Environ. Health Perspect. 121, 1378-1384. https://doi.org/10.1289/ehp.1306667.

Phung, D.T., Connell, D., Miller, G., Hodge, M., Patel, R., Cheng, R., Abeyewardene, M., $\mathrm{Chu}, \mathrm{C} ., 2$ 2012. Biological monitoring of chlorpyrifos exposure to rice farmers in Vietnam. Chemosphere 87 (4), 294-300. https://doi.org/10.1016/j.chemosphere. 2011.11.075.

Riederer, A.M., Bartell, S.M., Barr, D.B., Ryan, P.B., 2008. Diet and nondiet predictors of urinary 3-Phenoxybenzoic acid in NHANES 1999-2002. Environ. Health Perspect. 116, 1015-1022. https://doi.org/10.1289/ehp.11082.

Roca, M., Miralles-Marco, A., Ferré, J., Pérez, R., Yusà, V., 2014. Biomonitoring exposure assessment to contemporary pesticides in a school children population of Spain. Environ. Res. 131, 77-85. https://doi.org/10.1016/j.envres.2014.02.009.

Saillenfait, A.-M., Ndiaye, D., Sabaté, J.-P., 2015. Pyrethroids: exposure and health effects - an update. Int. J. Hyg. Environ. Health 218 (3), 281-292. https://doi.org/10.1016/ j.ijheh.2015.01.002.

Schoeters, G., Colles, A., Hond, E.D., Croes, K., Vrijens, J., Baeyens, W., Nelen, V., Mieroop, E.V.D., Covaci, A., Bruckers, L., et al., 2011. Chapter 2F: the Flemish environment and health study (FLEHS) - second survey (2007-2011): establishing reference values for biomarkers of exposure in the Flemish population. Biomarkers and Human Biomonitoring. pp. 135-165. https://doi.org/10.1039/978184973337300135.

Shalat, S.L., Donnelly, K.C., Freeman, N.C., Calvin, J.A., Ramesh, S., Jimenez, M., Black, K., Coutinho, C., Needham, L.L., Barr, D.B., et al., 2003. Nondietary ingestion of pesticides by children in an agricultural community on the US/Mexico border: preliminary results. J. Expo. Sci. Environ. Epidemiol. 13, 42-50. https://doi.org/10. 1038/sj.jea.7500249.

Sheldon, L.S., 2006. Chapter 42 - exposure framework. In: Krieger, R. (Ed.), Hayes' Handbook of Pesticide Toxicology, 3rd edition. Academic Press, New York, pp. 971-976.

Sircu, R., Pinzaru, I., Opopol, N., Scurtu, R., 2015. Health risk related to the intake of pesticides in the Republic of Moldova. Int. J. Adv. Res. (Indore) 3, 628-633.

Sudakin, D.L., Stone, D.L., 2011. Dialkyl phosphates as biomarkers of organophosphates: the current divide between epidemiology and clinical toxicology. Clin. Toxicol. 49, 771-781. https://doi.org/10.3109/15563650.2011.624101.

Trunnelle, K.J., Bennett, D.H., Tulve, N.S., Clifton, M.S., Davis, M.D., Calafat, A.M., Moran, R., Tancredi, D.J., Hertz-Picciotto, I., 2014. Urinary Pyrethroid and Chlorpyrifos Metabolite Concentrations in Northern California Families and Thei Relationship to Indoor Residential Insecticide Levels, Part of the Study of Use of Products and Exposure Related Behavior (SUPERB). Environ. Sci. Technol. 48, 1931-1939.

US EPA, 2015. Chapter 6- inhalation rates. Exposure Factors Handbook. Last accessed on September 18, 2019. https://www.epa.gov/sites/production/files/2015-09/ documents/efh-chapter06.pdf.

Wang, N., Huang, M., Guo, X., Lin, P., 2016. Urinary metabolites of organophosphate and pyrethroid pesticides and neurobehavioral effects in chinese children. Environ. Sc. Technol. 50, 9627-9635. https://doi.org/10.1021/acs.est.6b01219.

Weiss, B., Amler, S., Amler, R., 2004. Pesticides. Pediatrics 113, 1030-1036.

Wong, W.W.K., Yau, A.T.C., Chung, S.W.C., Lam, C., Ma, S., Ho, Y.Y., Xiao, Y., 2014. Dietary exposure of Hong Kong adults to pesticide residues: results of the first hong kong total diet study. Food Addit. Contam. Part A Chem. Anal. Control Expo. Risk Assess. 31, 852-871. https://doi.org/10.1080/19440049.2014.900573.

World Health Organization (WHO), 2019. Human Biomonitoring: Facts and Figures. Available on http://www.euro.who.int/en/media-centre/events/events/2015/04/ ehp-mid-term-review/publications/human-biomonitoring-facts-and-figures. Last accessed on September 18.

Yao, Y., Tuduri, L., Harner, T., Blanchard, P., Waite, D., Poissant, L., Murphy, C., Belzer, W., Aulagnier, F., Li, Y.-F., Sverkog, E., 2006. Spatial and temporal distribution of pesticide air concentrations in Canadian agricultural regions. Atmos. Environ. 40, 4339-4351. https://doi.org/10.1016/j.atmosenv.2006.03.039.

Yusa, V., Millet, M., Coscolla, C., Pardo, O., Roca, M., 2015. Occurrence of biomarkers of pesticide exposure in non-invasive human specimens. Chemosphere 139, 91-108. https://doi.org/10.1016/j.chemosphere.2015.05.082. 